\title{
Laboreal
}

Volume $5 \mathrm{~N}^{\circ} 1$ | 2009

Ergonomia e desenvolvimento sustentável

\section{Análise ergonómica da actividade, formação e transformação do trabalho : opções para um desenvolvimento durável}

Análisis ergonómico de la actividad, formación y transformación del trabajo :

opciones para un desarrollo durable

Analyse ergonomique de l'activité, formation et transformation du travail :

options pour un développement durable

Ergonomic analysis of the activity, training and work transformation : options

for durable development

Marianne Lacomblez e Ricardo Vasconcelos

\section{OpenEdition}

\section{Journals}

Edição electrónica

URL: http://journals.openedition.org/laboreal/10388

DOI: $10.4000 /$ laboreal. 10388

ISSN: 1646-5237

Editora

Universidade do Porto

Refêrencia eletrónica

Marianne Lacomblez e Ricardo Vasconcelos, « Análise ergonómica da actividade, formação e

transformação do trabalho : opções para um desenvolvimento durável », Laboreal [Online], Volume 5

$\mathrm{N}^{0} 1$ | 2009, posto online no dia 01 julho 2009, consultado o 10 outubro 2019. URL : http://

journals.openedition.org/laboreal/10388; DOI : 10.4000/laboreal.10388

Este documento foi criado de forma automática no dia 10 outubro 2019.

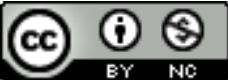

Laboreal está licenciado com uma Licença Creative Commons - Atribuição-NãoComercial 4.0 Internacional. 


\section{Análise ergonómica da actividade, formação e transformação do trabalho : opções para um desenvolvimento durável}

Análisis ergonómico de la actividad, formación y transformación del trabajo : opciones para un desarrollo durable

Analyse ergonomique de l'activité, formation et transformation du travail :

options pour un développement durable

Ergonomic analysis of the activity, training and work transformation : options for durable development

Marianne Lacomblez e Ricardo Vasconcelos

\section{NOTA DO EDITOR}

Manuscrito recebido em : Abril/2009

Aceite após peritagem em : Junho/2009

\section{Introdução}

1 A noção de desenvolvimento durável tem suportado projectos diversos e frequentemente contraditórios, obrigando sempre a levantar a questão "de que desenvolvimento falamos?" (Lacomblez, 2008). Existe contudo uma constante nas diferentes interpretações avançadas: a de colocar o bem-estar do ser humano no centro da dinâmica evolutiva das regiões do mundo, impondo o debate a propósito das consequências, a este nível, das estratégias definidas para um crescimento económico. 
2 Ora, se partirmos do paradigma fundador da ergonomia, não podemos deixar de notar como o seu projecto esteve, desde o início da sua afirmação, intrinsecamente associado ao de um desenvolvimento durável. Assumindo o desafio de que é possível conciliar a procura de um equilíbrio psicofisiológico dos trabalhadores com uma eficiência do trabalho (Myers, 1920), a opção foi manifestamente de tentar impor à preponderância económica, preocupações de natureza social e de defesa do direito à saúde. Presente em pesquisas que marcaram o inicio do Sec. XX período conhecido pela importância crescente desta polémica nos países industrializados (Polanyi, 1983) esta postura passou a ser mais expressamente adoptada, no período posterior à segunda guerra mundial, por aqueles que defendiam a necessária " adaptação do trabalho ao homem " e advogavam que a procura da produtividade não pode, humanamente, ser concebida sem uma melhoria simultânea das condições de trabalho (Albou et al., 1962).

ento, a história da ergonomia e das disciplinas científicas que se associaram ao seu projecto, patenteou como esse desafio nem sempre é fácil de sustentar, exigindo aos que se identificam com este modelo de intervenção uma vigilância permanente, uma atenção constante ao custo humano de decisões essencialmente orientadas pela procura da rentabilidade do trabalho. Talvez por isso a ergonomia tenha acabado por ser uma propedêutica (Schwartz, 1996) para uma reflexão em torno das exigências de um desenvolvimento durável.

\section{A formação em análise ergonómica do trabalho}

4 Em termos metodológicos, a ergonomia pretende compreender o trabalho para, progressivamente, definir vias possíveis para a sua transformação (Guérin, Laville, Daniellou, Duraffourg \& Kerguelen, 2001). A aposta situa-se então no plano da modificação das condições oferecidas para a realização do trabalho, recusando que sejam apenas os próprios trabalhadores a transformar o uso de si em razão dos imperativos de uma lógica alheia ao seu equilíbrio. Afastam-se deste modo os cenários de intervenção essencialmente orientados por objectivos de mudança do comportamento.

5 Todavia, alguns ergónomos mantiveram um certo interesse pelas potencialidades da intervenção formativa, considerando-a uma alavanca para a acção, uma passagem útil para uma difusão mais alargada do projecto da ergonomia. A sua conviç̧ão é a de que a melhoria das condições de trabalho não depende unicamente dos conhecimentos científicos e técnicos, pois exige igualmente determinação por parte dos actores envolvidos. Neste sentido, Alain Wisner assumiu sem dúvida um papel pioneiro quando defendeu, nos anos 60 do séc. $\mathrm{XX}$, a introdução de uma disciplina de ergonomia na formação dos engenheiros.

6 Mais tarde, a partir dos anos 70, Antoine Laville e Catherine Teiger (Teiger \& Laville, 1991) evocaram a mesma intenção quando deram resposta ao pedido de organizações sindicais, na altura estimuladas pelas responsabilidades que lhes foram atribuídas por numerosos dispositivos legais em matéria de controlo das características das situações de trabalho e dos seus efeitos na saúde. Este encontro entre cientistas e militantes sindicais revelou-se particularmente estimulante e os modelos de intervenção que daí resultaram, acabaram por assumir um lugar de destaque no seio de uma nova praxis, igualmente emergente noutros países (Lacomblez \& Teiger, 2006). Contribuiu-se assim para a abertura de uma nova via de abordagens, assentes numa outra conceptualização 
das relações entre conhecimento e acção, no âmbito do que hoje é habitual designar "paradigma da formação dos actores" (Teiger \& Lacomblez, 2005 ; 2006). Afastamo-nos aqui, claramente, de uma concepção tradicional da aprendizagem, nomeadamente pelo reconhecimento dos saberes construído com a experiência dos trabalhadores, pela valorização do seu ponto de vista e pela recusa em definir o formador como perito fechado ao potencial que encerra a dinâmica do seu encontro com os formandos.

7 Assim, o modelo prevalente nesta "nova via" de acções estrutura-se em torno dos seguintes princípios :

- Os conhecimentos iniciais dos formandos são integrados em descrições pormenorizadas da sua actividade de trabalho e dos efeitos sentidos no plano da saúde; estas descrições são seguidamente enquadradas e desenvolvidas através de um "questionamento ergonómico", que é de tipo maiêutico já que é conduzido pelos formadores de modo a estimular a actividade reflexiva e a permitir a "tradução em palavras" daquilo que nem sempre se sabe que se sabe ;

- Os conhecimentos ergonómicos são evocados de forma "oportuna" e não de acordo com um programa pré-estabelecido: um vai e vem constante entre as observações (Teiger et al., 1977) dos formandos e as análises dos ergónomos permite a discussão dos dados obtidos e a construção gradual de hipóteses. Três tipos de conhecimentos são então referidos, de modo a conceber a acção sobre o trabalho, o seu acompanhamento e a sua continuidade: conhecimentos "ergonómicos" (modelos de actividade, relações entre saúde e trabalho); conhecimentos "metodológicos" (a abordagem e os métodos da análise ergonómica do trabalho); e conhecimentos "estratégicos" (análise das condições de viabilidade dos projectos de transformação do trabalho : constrangimentos e recursos).

- A atenção atribuída à linguagem é central na confrontação dos conhecimentos da experiência dos participantes e dos conhecimentos científicos dos ergónomos: É a compreensão mútua entre uma linguagem de tipo "narrativo" e uma outra de tipo "interpretativo" que irá permitir a passagem da formulação de problemas à sua desindividualização, à sua formalização e à reconstrução de uma linguagem de tipo argumentativo (Habermas, 1987 ; Ferry, 1991).

8 A aprendizagem da análise ergonómica do trabalho é aqui "um instrumento para a acção" dos próprios formandos. A perspectiva é construtivista, no sentido piagetiano : a aquisição de um conhecimento não passa pela capacidade de o "reproduzir", mas sim por um processo que permite concretiza-lo, "agir" sobre ele, apropria-lo e transformálo (Piaget, 1974).

Contudo, esta aprendizagem não é de sentido único : a abordagem é reciprocamente formativa e inscrita num percurso de que resultarão novos conhecimentos. 0 encontro entre os dois registros de saberes permite não só uma descrição mas, sobretudo, uma compreensão dos fenómenos em causa contribuindo para a definição de acções visando a transformação do trabalho, mas igualmente para a renovação das representações e interpretações do que acontece nos locais de trabalho. Os conhecimentos produzidos beneficiam em consequência de uma dupla validação, passando a ser difundidos e discutidos, por um lado, em meio sindical, e por outro lado, no mundo da ergonomia e das disciplinas afins.

Esta dinâmica da relação entre formandos e formadores é gerada pelas potencialidades da análise ergonómica do trabalho, quando definida como objecto da intervenção formativa. Mas esta opção de co-aprendizagem revela e requer além disso um projecto de sociedade em que formandos e formadores sejam abarcados, a longo prazo, numa 
análise crítica das condições de trabalho, das suas evoluções, do que estas pressupõem, determinam e exigem, e das alternativas possíveis.

\section{A análise do trabalho como meio para a formação profissional}

11 Após a segunda guerra mundial e até os anos 70, o "pedido social" mobilizou regularmente psicólogos do trabalho a contribuírem para a concepção de programas de formação adequados às necessidades que emergiam das reestruturações dos processos de produção. Jacques Leplat (1955) foi dos primeiros autores a realçar a complementaridade das relações entre a análise do trabalho (que fornece elementos úteis para a concepção de programas para uma formação "racional") e a formação (que constitui um meio para verificar as hipóteses que suscitou na análise).

12 Mas o contributo não pretende ser unicamente metodológico : ao demonstrar a mais valia de uma análise da actividade de trabalho, os autores querem também realçar a complexidade do trabalho humano e refutar o reducionismo das abordagens que encaram o trabalhador como simples apêndice falível dos equipamentos técnicos.

O debate não é novo, mas a argumentação vai sendo enriquecida por pesquisas atentas à construção progressiva, pelo operador, de um bom conhecimento daquilo que exigem as características técnico-organizacionais da sua situação de trabalho : a sua actividade de "regulação" é descrita, nas suas variadas configurações, como procurando, num quadro temporal sempre constrangedor,"manter um certo equilíbrio ou um certo acordo entre imperativos em princípio opostos" (Faverge, 1966, p. 56, tradução livre).

Levados a cabo em diferentes sectores, a propósito de actividades exercidas em tarefas de complexidade diversa, estes estudos impuseram uma nova abordagem da experiência profissional, dando igualmente uma outra visibilidade a um registo de conhecimentos até aí nem sempre valorizado.

Esta conjuntura científica contribuiu sem dúvida para a confirmação da convicção de alguns de que há que privilegiar novos modos de formação profissional, consagrando uma ruptura com as concepções da aprendizagem baseadas no princípio da repetição dos gestos ou comportamentos "correctos" predefinidos. Neste quadro, algumas pesquisas foram decisivas para conferir um novo estatuto a este princípio da análise do trabalho como meio para a concepção da acção de formação. O estudo de Bisseret et Enard (1969), por exemplo, ainda hoje é frequentemente referido pelo interesse de uma análise da actividade dos controladores aéreos, que em muito contribuiu para a elaboração de um programa de formação adequado e pertinente.

16 A partir de então, a lição tornou-se recorrente : "em vez de privilegiar um diagnóstico enraizado no pressuposto de um conhecimento global do processo de trabalho - o que seria lógico no âmbito de um ensino tradicional -, somos conduzidos a inverter esta posição. Os estudos no terreno fazem-nos pensar que a familiaridade e o contacto quotidiano com os disfuncionamentos constituem, na realidade, o ponto de partida para um conhecimento do processo que é diferente daquele, inalterável, dos manuais de formação" (De Keyser, 1972, p. 45, tradução livre).

17 Todavia, esta via de pesquisa, fundamental na história mais recente da ergonomia, ficou, durante largos anos, pouco conhecida noutras disciplinas científicas. E foi preciso 
o contexto dos anos 80 do séc. XX para ver reunidas as condições propícias a um interesse mais alargado por esta abordagem.

18 A crise que se instala neste período é profunda. Ela é económica, primeiro, e é seguida do inevitável cortejo das consequências sociais induzidas pelas reorganizações e pelas "compressões" de mão-de-obra. Mas a ruptura é também ideológica, abrangendo o declínio dos movimentos colectivos, o renascer das convicções do liberalismo económico, o regresso de certas formas de individualismo (Castel, 1999) e a convicção de que as soluções para as dificuldades passam sobretudo pelas opções de cada um.

Nos locais de trabalho, as mudanças transformam ao mesmo tempo a dinâmica das relações entre os parceiros sociais, a relação com o emprego e o conteúdo das funções : a procura de uma outra flexibilidade nos processos de produção face aos imponderáveis do mercado reconfigura progressivamente as empresas em cenários de geometria variável.

No âmbito desta nova lógica, fala-se cada vez menos de "qualificação", cuja caracterização resulta de uma relação social (Naville, 1956) e cada vez mais das "competências" (Stroobants, 1993 ; 2006) do operador, isto é das qualidades valorizadas pela hierarquia e demonstradas (ou não) por cada um no exercício da função. Por outro lado, tendencialmente, este operador deixa de ser visto como simples executante : é esperado dele que seja capaz de assumir iniciativas, respondendo de modo adequado à maioria das modificações e acontecimentos imprevistos da produção. 0 principio de um processo organizacional (Maggi 2006) impõe-se e, conjuntamente, o da necessidade de uma outra dinâmica na gestão do aperfeiçoamento das competências dos membros da empresa.

21 Contribuir para a "formação de competências" assume assim um lugar de destaque crescente. São convocados os contributos da ergonomia ou da psicologia do trabalho (que passaram a ser designadas "da actividade"), já familiarizadas e sensíveis ao que revela a análise atenta do desempenho das funções em situações reais. Como escreveram Leplat e de Montmollin (2001, p. 7, tradução livre) "os métodos de descrição das competências procedem sempre de análises bottom up : análises finas e locais do seu trabalho (o do operador) e sobretudo das suas actividades". A mudança de perspectiva e a ideia de que "para serem eficazes, as formações profissionais têm de ser concebidas após análise dos objectivos, das competências já adquiridas e do comportamento no trabalho dos operadores experimentados" (Falzon \& Teiger, 1999, p. 171) atravessa então, também, o mundo dos formadores e das ciências da educação. Estes vêem-se solicitados a afastarem-se do privilégio atribuído a conteúdos de formação teórico-abstractos, baseados numa representação predefinida daquilo que o trabalhador alegadamente precisa, e a aproximarem-se das questões colocadas efectivamente ao operador quando se confronta com a sua situação de trabalho. A ancoragem da formação no trabalho real irá então exigir cada vez mais do formador : É lhe exigido possuir o domínio técnico suficiente de uma área de actividade particular e a capacidade didáctica da sua transmissão; ser um bom analista das situações de trabalho reais ; ser capaz de ajudar os formandos na formalização da sua actividade e de objectivar a sua relação singular com esta actividade (Jobert, 1993).

Neste contexto, passa a ser óbvio que a tradição acima referida da ergonomia e da psicologia do trabalho oferecem um acervo que não deixa dúvidas sobre o seu interesse teórico e metodológico. Gérard Vergnaud foi explícito neste reconhecimento, integrando-o nas suas pesquisas em ciências da educação. Deu origem à "didáctica 
profissional" (Vergnaud, 1992), disciplina cujo desafio fundador interpelou o risco de uma marginalização dos adultos em dificuldade, desempregados de longa duração ou trabalhadores de baixo nível de qualificação.

No âmbito deste programa de pesquisa e de intervenção, um projecto de desenvolvimento é igualmente referido: o de uma "sociedade do conhecimento" no seio da qual a intervenção privilegiada consiste em potenciar uma maior adaptabilidade às novas exigências e um acesso alargado aos conhecimentos que estão a emergir, nomeadamente, pelas reviravoltas do mundo do trabalho. Deste modo, a questão central passa a ser a dos processos de aquisição, de partilha e de transmissão daquelas competências que não são essencialmente constituídas por saberes académicos, embora entrem em diálogo com estes. A análise da actividade de trabalho é valorizada pelo que dá a ver do corpo de saberes convocados pelo operador. Aqui, o papel do analista enraíza-se na hipótese de que a forma predicativa do conhecimento está quase sempre em atraso relativamente à sua forma operatória : trata-se então de privilegiar a sua formalização. Nesta via, uma verdadeira escola científica acabou por federar pesquisas acerca de uma matriz epistemológica cuja relativa autonomia se foi afirmando (Samurcay \& Pastré, 2004).

\section{Quando as duas perspectivas se encontram}

No entanto, e obviamente, a atenção consagrada à elaboração e adequação de programas de formação não chega para levar a bom porto o projecto de uma inserção bem conseguida de todos nas reestruturações das empresas. Esta não deve, aliás, ser vista como um momento mas como um processo. A acção de formação não pode ser isolada de um processo de mudança que, na realidade e inevitavelmente, a ultrapassa. A formação não é suficiente em si mesma. Ela não constitui, por si só, a via de um desenvolvimento real, congruente e durável - mesmo que seja cuidadosamente concebida, preparada e implementada.

Face às armadilhas de uma tentação responsabilizadora em que a preocupação central é circunscrita à capacidade dos trabalhadores para resolverem as dificuldades com que se confrontam, a ergonomia volta a assumir o direito à palavra. Lembra que é preciso interrogarmo-nos a propósito das condições concretas em que as competências adquiridas pelos formandos terão de ser utilizadas na situação real de produção. $\mathrm{Na}$ verdade, se as pressões temporais se revelarem demasiado fortes, se o número de assalariados não for suficiente para assegurar os fins definidos, se a organização do trabalho não for repensada a partir dos objectivos renovados, a formação adquirida irá perder o seu sentido. Pior ainda : pode acabar por desestabilizar os formandos (Cru, 2000), tendo-os encaminhado para a aquisição de novos saberes que se revelam impossíveis de concretizar.

Trata-se de efeitos perversos que, inequivocamente, podem ter incidência nomeadamente no plano da preservação da saúde e da segurança (Chatigny, 2001). Mas está também em jogo a estabilidade do emprego dos ex-formandos, pois nessas circunstâncias, correm o risco de transmitir aos seus superiores hierárquicos a imagem de uma falta de competências, avaliada por estes como profundamente ilegítima no seguimento da participação numa acção de formação, principalmente se tiver sido cuidadosamente preparada. 

jovens investigadores que procuraram, nas suas reservas de argumentos e de técnicas de intervenção, o sopro necessário para ultrapassar as limitações de actuações demasiado pontuais. Assim, quando o contexto o possibilita, são elaborados cenários de intervenção que, num diálogo sustentado com os formandos, pretendem ancorar a orientação das finalidades da acção de formação numa análise do real das evoluções das situações de trabalho e num acompanhamento atento das transformações em curso, bem como dos riscos profissionais prevalentes e decorrentes.

O lema geral é que as mudanças técnico-organizacionais não podem ser decididas abstractamente e de forma definitiva, com o único apoio dos recursos técnicocientíficos e sem uma ancoragem na sempre renovada actividade real de trabalho, onde se exprimem concretamente dificuldades e dinâmicas contraditórias. Partindo de um bom conhecimento da actividade dos formandos e dos efeitos já constatados da sua não-consideração, o objectivo é o de potenciar o contributo dos protagonistas encontrados num processo de progressiva apropriação da análise ergonómica do trabalho, criando-se assim condições para um "alargamento visível" da sua valorização integrado no próprio evoluir das unidades de produção.

Aqui, a aquisição pelos trabalhadores dos princípios da análise da actividade de trabalho ocupa um lugar de destaque. Contudo, se considerarmos as duas tradições apresentadas no início deste texto, o estatuto desta análise passa a ser misto : ela é, simultaneamente, "objecto" para cujas potencialidades se sensibiliza os formandos, a partir do progressivo conhecimento das situações de trabalho em questão e "meio" para as (re) orientações das finalidades da intervenção que o percurso comum vai tornando evidentes e pertinentes.

30 Neste caso, é ultrapassada a distinção entre as duas funções da análise do trabalho, próprias ao "paradigma de formação dos actores" ou aos projectos que se situam na axiológica da didáctica profissional.

31 Contudo, a determinação em demonstrar a mais valia de uma incursão simultânea nas duas tradições revela, no terreno das empresas, o carácter insubstituível da presença atenta e activa do formador, verdadeiro mediador de um processo que exige uma vigilância deontológica e metodológica constante (Petit, 2008 ; Vasconcelos, 2008). O ergónomo, ou o psicólogo do trabalho, assume um papel que se estende no longo prazo, numa actuação que o confronta com a expressão diária das medidas implementadas nas reestruturações das empresas, expressão esta que vai, aos poucos, transformando as formas de mobilização da actividade humana.

32 A perspectiva assumida é então, também, a de uma análise que tenta deslindar, passo a passo, os factores que vão evoluindo, entrecruzando os seus efeitos e se revelam na actividade concreta de quem trabalha. É visada uma outra compreensão do que está em jogo nas evoluções do mundo do trabalho - querendo, deste modo, contribuir para a procura de alternativas. Este alargamento e acompanhamento da aç̧ão de formação e das acções de transformação que se alimentam mutuamente, implica, desde logo, uma diversificação dos actores da formação e novos desafios para o investigador/formador. A ancoragem da formação num projecto interdependente de transformação das formas de organização e das condições de trabalho, requer um investimento na análise e na auto-análise das actividades de trabalho que não pode cingir-se aos operadores, cujo espectro de decisão no que toca à transformação do seu trabalho é bastante reduzido, sendo no entanto essencial à congruência potencial das acções a implementar e ao 
acompanhamento da sua evolução, como desde há muito a ergonomia tem vindo a demonstrar. Nesse sentido, e para citar apenas um exemplo, trabalhos recentes (Vasconcelos, 2008) procuram articular no processo formativo momentos de autoanálise guiada da actividade de operadores industriais, em posto de trabalho, com momentos em que os seus resultados são partilhados e discutidos num grupo de pares, mas onde estão também representados outros actores "relativamente pertinentes" para as actividades e os problemas em discussão (técnicos de segurança, técnicos da manutenção, supervisores de produção) assim como para o esboçar de soluções possíveis e organizacionalmente congruentes. Estes outros actores são também progressivamente integrados nos momentos de auto-análise em posto de trabalho, que se transformam em espaços de compreensão das actividades e problemas em questão, bem como do método que conduz à sua "descoberta" e explicitação. Balanços sectoriais (com responsáveis pela segurança, pela engenharia, pela produção) promovidos a par e passo com a evolução do trabalho com o grupo de "formandos" completam o dispositivo e procuram assegurar, simultaneamente, uma visão amplamente partilhada dos problemas emergentes e dos dilemas que caracterizam as actividades de trabalho em geral, a validação e aperfeiçoamento interdisciplinar das soluções de transformação que vão sendo avançadas (também com o contributo destes decisores, que se repercute nas sessões subsequentes de trabalho com o grupo), e o necessário envolvimento da hierarquia essencial ao desencadear das acções concretas de transformação das condições de execução.

\section{Opções em termos de desenvolvimento}

Propor um contributo para o desenvolvimento individual é uma constante dos projectos definidos no âmbito das acções referidas, qualquer que seja o paradigma adoptado. Igualmente partilhada é a concepção global do desenvolvimento da sociedade, que todos os autores pretendem não submetida, unicamente, a uma dinâmica económica : o critério da igualdade, o combate contra as assimetrias sociais e o direito a uma vida decente atravessam as três perspectivas delineadas. No entanto, a caracterização do que subentende este desenvolvimento é variável.

o paradigma da formação dos actores (cf. ponto 2) projecta-se numa vontade de criar condições para uma outra compreensão do que determina a vida de quem trabalha, querendo abrir a via de uma análise das alternativas possíveis (Rolle, 1997). A questão do desenvolvimento potencial do formando é central, mas ela é tratada pela via das condições em que este desenvolvimento pode (ou não) ser concretizado.

Aqui, a perspectiva é intrinsecamente colectiva: não só pela dinâmica da reflexão desencadeada, como pela definição dos problemas que sucessivamente são objecto de análise, como ainda pelas finalidades delineadas para as possíveis intervenções.

Por fim, o terreno da intervenção é deliberadamente exterior à empresa : considera-se que as especificidades das condições de trabalho devem ser objecto de debate e de negociação e a opção é a de auxiliar as organizações sindicais na defesa do direito à saúde e à segurança. Neste sentido, formadores e formandos associam-se numa análise em que os saberes convocados se encontram numa relação não hierarquizada, enriquecendo-se cada um com o que daí irá resultar.

37 No paradigma da didáctica profissional (cf. no ponto 3), revelador do projecto das práticas formativas valorizado nos últimos 15 anos, o desafio é o de um acesso alargado 
ao conhecimento, nomeadamente devido à importância crescente de competências "críticas", não essencialmente académicas, numa sociedade em profunda evolução. Logicamente, as questões centrais são as dos processos de aquisição, de partilha e de transmissão de saberes, "extraídos" do que revela a actividade do trabalho experiente, e formalizados pelo analista.

Mas aqui o processo de desenvolvimento está mais directamente relacionado com preocupações económicas, embora a intenção seja claramente a de contrapor alternativas ao "mercado-árbitro". Quanto ao terreno de intervenção, podendo ser periférico ao da empresa e integrar centros de formação profissional, sempre é predefinido a partir das exigências dos locais de trabalho e suas evoluções, reais ou prováveis.

39 Transposto tal e qual para o contexto da empresa, este paradigma corre o risco de ser submetido ao primado dos valores do mercado e da rentabilidade de curto prazo que aí costumam predominar.

40 Capitalizando as experiências anteriores, a nova geração de investigadores a que fizemos referência (cf. ponto 4), revela-se particularmente atenta à necessidade de uma reconfiguração dos cenários de intervenção formativa nos locais de trabalho. Nessas abordagens, e apesar do "desconforto intelectual" (Schwartz, 1998) que pode suscitar, a vigilância ética e metodológica faz parte integrante do projecto e serve explicitamente de suporte, de "fio condutor" para a salvaguarda de um quadro analítico onde a evolução dos saberes profissionais nunca é dissociada da sua relação com os riscos para a integridade física e mental (Vasconcelos, 2008 ; Ouellet \& Vézina, 2008).

41 Trata-se de estudos que, ao fazer o balanço das tradições anteriores e reconhecendo o legado que transmitiram, constatam que o mundo do trabalho está a mudar e assumem que os paradigmas outrora definidos ganhariam em sofrer processos de diferenciação.

42 Assumindo esta perspectiva, o debate em torno do desenvolvimento realça os efeitos prejudicais das mudanças exógenas, definidas a partir de análises afastadas das situações que pretendem transformar, "sem se instruir sobre as actividades de trabalho, os seus recursos, as suas potencialidades, as suas reservas de alternativas" (Schwartz, Adriano \& Abderrahman, 2008). Coloca assim a análise (permanente) das actividades de trabalho (as próprias e as dos outros) no centro do debate sobre o desenvolvimento durável, assumindo a análise das actividades como guardiã deste desenvolvimento.

43 A intenção é assim, necessariamente, a de promover a analise de um presente comprido, historicamente ancorado e permanente construtor do futuro, mas sem ficar amarrado a suportes teóricometodológicos pré-definidos ou a opções tradicionais, abrindose a novas grelhas de interpretação, a novos parceiros de intervenção, a novos e interdependentes sujeitos/ objectos de análise. E isto independentemente da sua categoria profissional ou do seu estatuto de poder, mas antes em função da sua relativa pertinência para o desenvolvimento coerente do sistema de actividades em questão, do qual, temporária ou permanentemente, o ergónomo/ formador e os seus modelos e métodos são parte integrante. Trata-se, de certa forma, de contaminar os espaços de trabalho e de investigação com a clara consciência de um certo modelo de humanidade que nos faça ver o nosso semelhante, seja ele operador ou decisor, como alguém que está "em actividade", isto é, alguém - como cada um de nós - cuja actividade é lugar de gestão de debates de normas, lugar de resingularização permanente da situação (Schwartz \& Durrive, 2003). Por outro lado, de certa forma, os autores aqui referidos 
vão ao encontro de uma nova geração de sociólogos do trabalho que, face ao incremento de práticas de desmantelamento do que parecia fazer parte de um universo de evidências, se recusa em recordar com nostalgia "um mundo no seio do qual o Estado teria domesticado o mercado, o pleno emprego teria sido um facto, o movimento operário teria estado no centro das lutas e dos conflitos sociais essenciais e, em definitivo, a política teria tido mais peso sobre o económico : um mundo do qual, hoje, só restariam ruínas" (Garcia Lopez, 2006, p.11, tradução livre), Procuram, em consequência, afastar-se de categorias de análise de um tempo em que tiveram sentido, agora definidas pela negativa. Fazem-no por estas se arriscarem a empobrecer, não só a compreensão das evoluções em curso, mas ainda a procura de alternativas ao que se afigura necessário mudar.

O que a experiência destes novos projectos testemunha é que, inevitavelmente e dependendo do "mundo" de onde são originários os diferentes actores envolvidos (académico, da produção, da gestão, ...), há sempre riscos, ganhos e perdas, debates e conflitos de poder, de normas e valores, inerentes aos processos de (auto)questionamento despoletados e a cada uma das actividades em causa, que obstaculizam o sentido que cada um desses actores, autónoma e idealmente, daria ao desenvolvimento das questões e das acções em debate. Todos eles vêem e prevêem riscos de que a situação não evolua no sentido idealizado por si ou pelo seu "mundo" ; todos eles temem que o que de bom lhes trouxe o processo formativo/transformativo seja, mais cedo ou mais tarde, "atropelado" pela locomotiva do quotidiano. No que aos investigadores e interventores em ergonomia e em psicologia do trabalho diz respeito, mais do que um risco, vê-se nestas resistências uma oportunidade para trazer para a mesa da discussão esses diferentes "desconfortos", tornando-os objecto permanente e explícito do real da actividade (Clot, 2006) de cada um, o que está longe de ser um processo evidente ou espontâneo, mas que é visto como a chave para o desenvolvimento durável das actividades em questão, aqui naturalmente incluída a actividade do investigador/formador.

Parece por isso clara a dependência destas novas abordagens de investigação-formaçãotransformação em relação ao olhar integrador e à acção do investigador/formador que as conduz, negoceia e dinamiza. E isto não constitui uma ameaça ao seu desenvolvimento durável em contexto. É antes, apenas, mais um elemento do real a analisar e respeitar, mais um desafio que a própria actividade de investigadores/ interventores coloca, mais uma etapa de um percurso renovadamente alimentado pela convicção de que, sem um conhecimento preciso e reavivado do trabalho se correrá o risco de tornar o "desenvolvimento" "uma vã palavra que encontra dificuldade em entrar na vida para a transformar e a tornar melhor" (Nouroudine, 2008, p. 31).

\section{BIBLIOGRAFIA}

Albou, P., Baron, P., Bonnardel, R., Bouisset, S., Fournier, E., Gillon, JJ., Le Grand, Y., Leplat, J., Scherrer \& J., Wisner, A. (1962). L'adaptation du travail à l'homme. Paris : PUF. 
Bisseret, A. \& Enard, C. (1969). Le problème de la structuration de l'apprentissage d'un travail complexe : une méthode de formation par interaction constante des unités programmées (MICUP). Bulletin de Psychologie, 284, 632-648.

Castel, R. (1999). Libéralisme et individualisme. In Questions au libéralisme. Bruxelles : Faculté universitaire de Saint-Louis.

Chatigny, C. (2001). Les ressources de l'environnement : au cœur de la construction des savoirs professionnels en situation de travail et de la protection de la santé. Pistes, 3, 2, http:// www.pistes.uqam. ca/v3n2/articles/v3n2a7.htm

Clot, Y. (2006). A função psicológica do trabalho. Petrópolis : Editora Vozes.

Cru, D. (2000) Prévention et formes du dialogue social : mise en perspective historique. Revue de médecine du travail, XXVII, 2, 119-126.

De Keyser, V. (1972). Affidabilità ed esperierza. In : Affidabilità e sicurezza, Luxembourg : CEE (citado por M. Cesa Bianchi et G. Mantovani, Débat sur la notion d'opératoire. In J. Leplat et P. Bertelson, Eds, Hommage à Jean-Marie Faverge, 43-47. Le Travail Humain, 45, 1, nº especial).

Faverge, J.M. (1966). L'analyse du travail en terme de régulation. In J.M. Faverge, M. Olivier, J. Delahaut, P. Stephaneck \& J.C. Falmagne. (Eds.), L'ergonomie des processus industriels (pp. 3360). Bruxelles : Editions de l'Institut de Sociologie, Université de Bruxelles.

Falzon, P., \& Teiger, C. (1999) Ergonomia e formação. In P. Carré \& P. Caspar (Eds.), Tratado das ciências e das técnicas da formação (pp. 161-178). Lisboa : Ed. Piaget.

Ferry, J.M. (1991). Les puissances de l'expérience. Paris : Ed. du Cerf.

Garcia Lopez, J. (2006). Del "trabajo" al salariado (I) : Algunos modos de evacuar el cambio histórico de la teorización sociológica sobre el trabajo. Policopiado.

Guérin, F., Laville, A., Daniellou, F., Duraffourg, J. \& Kerguelen, A. (2001). Compreender o trabalho para transformá-lo. S. Paulo : Edgard Blücher.

Habermas, J. (1987). Théorie de l'agir communicationnel. Paris : Fayard.

Jobert, G. (1993). Les formateurs et le travail. Chronique d'une relation malheureuse. Education Permanente, 116, 7-18.

Lacomblez, M. (2008). A feminização dos meios de trabalho definidos em masculinidade : debates de normas e desenvolvimento. Laboreal, IV, 1, 39-45. http://laboreal.up.pt/revista/artigo.php? id $=48 \mathrm{u} 560 \mathrm{TV} 6582234396 ; ; 2493: 32$

Lacomblez, M.\& Teiger, C.(2006). Ergonomia, formaçõesetransformações. In : Pierre Falzon (Ed.), Ergonomia (pp. 587-602). São Paulo : Edgard Blücher.

Leplat, J. (1955). Quelques aspects de la formation à des tâches manuelles. Bulletin du CERP, IV, 4, 393-409; e Analyse du travail et formation. Bulletin du CERP, IV, 9, 175-184. In J. Leplat (2002). Psychologie de la formation. Jalons et perspectives. Toulouse : Octarès (pp. 9-23 e 55-62).

Leplat, J. \& de Montmollin, M. (2001). Préface. In J. Leplat \& M. de Montmollin (Eds.), Les competences en ergonomie (pp. 7-10). Toulouse : Octarès.

Maggi, B. (2006). Do agir organizacional. Um ponto de vista sobre o trabalho, o bem-estar, a aprendizagem. São Paulo : Edgard Blucher. Myers, C.S. (1920). Mind and Work. London : University of London Press. Naville, P. (1956). Essai sur la qualification du travail. Paris : Marcel Rivière. 
Nouroudine, A. (2008). O trabalho : componente esquecida no documento de estratégia de crescimento e de redução da pobreza nos Comores. Laboreal, IV, 1, 29-38, http://laboreal.up.pt/ revista/ artigo.php ?id =48u56oTV6582234396589 : ;3892

Ouellet, S. \& Vézina, N. (2008). Savoirs professionnels et prévention des TMS : réflexions conceptuelles et méthodologiques menant à leur identification et à la genèse de leur construction. Pistes, 1, 2, http://www.pistes.uqam.ca/v10n2/pdf/v10n2a5.pdf.

Petit, J. (2008). A intervenção ergonómica como dinâmica de aprendizagem : estudodecaso. Laboreal, IV, 2, 40-49, http://laboreal. up.pt/revista/artigo.php ?id =48u56TV65822346998;4:43 ; 62

Piaget, J. (1974). La prise de conscience. Paris : PUF.

Polanyi, K. (1983). La grande transformation - Aux origines politiques et économiques de notre temp. Paris : Gallimard.

Rolle, P. (1997). Pierre Naville, de la psychologie à la sociologie. L'orientation scolaire et professionnelle, 26, 2, 221-247.

Samurcay, R.\& Pastré, P. (2004). Recherchesendidactiqueprofessionnelle. Toulouse : Octarès.

Schwartz, Y. (1996). Ergonomie, philosophie et exterritorialité. In F. Daniellou (ed.), L'ergonomie en quête de ses principes (pp. 141182). Toulouse : Octarès.

Schwartz, Y. (1998). Travail et ergologie. In Schwartz, Y. (Dir.), Reconnaissances du travail - Pour comprendre une approche ergologique (pp. 1-37). Paris : PUF.

Schwartz, Y. \& Durrive, L. (2003). Travail \& Ergologie : Entretiens sur l'activité humaine.

Toulouse : Octares.

Schwartz, Y, Adriano, R. \& Abderrahman, F. (2008). Revisitar a actividade humana para colocar as questões do desenvolvimento : projecto de uma sinergia franco-lusófona. Laboreal, IV , 1, 10-22, http://laboreal. up.pt/revista/artigo.php ?id =48u56oTV65822346998; 6 73872

Stroobants, M. (1993). Savor-faire et compétences au travail. Bruxelles : Ed. de l'Université de Bruxelles.

Stroobants,M.(2006).Competência.Laboreal,2,(2),78-79.http://laboreal. up.pt/revista/artigo.php ? id $=37 \mathrm{t} 45 \mathrm{nSU} 547112278541422861$

Teiger, C., Dessors, D., Laville, A., Gadbois, C., Lantin, G., Kerguelen, A. \& Resche-Rigon, P. (1977). Renseignements téléphoniques avec lecture de microfiches sous contrainte temporelle. Paris : Laboratoire de Physiologie du travail - Ergonomie du CNAM, rapport $n^{\circ} 53$.

Teiger, C. \& Laville, A. (1991). L'apprentissage de l'analyse ergonomique du travail, outil d'une formation pour l'action. Travail et emploi, 1, 47, 53-62.

Teiger, C. \& Lacomblez, M. (2005). L'ergonomie et la trans-formation du travail et/ou des personnes (1). Education Permanente, 165, 9-28.

Teiger, C. \& Lacomblez, M. (2006). L'ergonomie et la trans-formation du travail et/ou des personnes (2). Education Permanente, 166, 9-28. Vasconcelos, R. (2008). O papel do psicólogo do trabalho e a tripolaridade dinâmica dos processos de transformação : contributo para a promoção da segurança e saúde no trabalho. Tese de doutoramento. Porto : FPCEUP.

Vergnaud, G. (1992). Qu'est-ce que la didactique ? En quoi peut-elle intéresser la formation des adultes peu qualifiés? Education Permanente, 111, 19-31. 


\section{RESUMOS}

Este artigo insere-se numa já longa tradição de estudos que, a partir do último terço do séc. XX, têm vindo a realçar o contributo da análise ergonómica do trabalho quando se trata de formação profissional e, particularmente, quando são abordadas questões relativas à formação contínua. Definem-se as principais perspectivas assumidas nessas abordagens : a formação de actores da prevenção em análise ergonómica do trabalho; a análise do trabalho enquanto meio para a formação profissional ; e uma terceira via que procura abarcar as duas perspectivas anteriores em projectos de formação-transformação das situações de trabalho. Evidencia-se nesta análise a importância atribuída à consideração da experiência adquirida ao longo de um percurso profissional e à sua valorização no âmbito de projectos de transformação dos processos produtivos. É neste quadro que a problemática do desenvolvimento durável emerge, embora revestindo várias acepções que se procurará caracterizar de forma diferencial.

El artículo se inscribe en una larga tradición de estudios que, desde los últimos treinta años del siglo veinte han venido a demostrar la contribución del análisis ergonómico del trabajo cuando se trata de formación profesional y, particularmente, cuando son abordadas cuestiones relativas a la formación continua. Se definen las principales perspectivas asumidas en estos abordajes: la formación de actores de la prevención en análisis ergonómico del trabajo ; el análisis del trabajo como medio para la formación profesional; y una tercera vía que intenta abarcar las dos perspectivas anteriores en proyectos de formación-transformación de las situaciones de trabajo. Se pone en evidencia en este análisis la importancia atribuida a la consideración de la experiencia adquirida durante un trayecto profesional y a su valorización en el ámbito de proyectos de transformación de los procesos productivos. Es en este marco que la problemática del desarrollo sostenible emerge, aunque asumiendo varias acepciones que se procurará caracterizar de forma diferencial.

Cet article s'insère dans le cadre d'une tradition d'études qui, à partir du dernier tiers du 20ème siècle, a mis en évidence la contribution potentielle de l'analyse ergonomique $\mathrm{du}$ travail lorsqu'on traite de formation professionnelle et, tout particulièrement, lorsque sont abordées des questions relatives à la formation continue. On définit les principales perspectives qui ont été assumées dans ces approches : la formation à l'analyse ergonomique du travail des acteurs de la prévention; l'analyse du travail en tant que moyen pour la formation professionnelle; et une troisième voie qui cherche à couvrir les deux perspectives antérieures au sein de projets de formation-transformation des situations de travail. On met en évidence l'importance attribuée à l'expérience acquise au long d'un parcours professionnel ainsi que sa valorisation dans le cadre de projets de transformation des processus productifs. C'est ici que la problématique du développement durable émerge, même si celle-ci revêt des acceptions différentes - que l'on a voulu caractériser.

This article is framed in a long lasting tradition of studies that, since the last third of the twentieth century, have been enhancing the contribution of ergonomic work analysis for professional training, particularly, when continuous training is at stake. The main perspectives assumed in these approaches are defined: the training of preventionists for ergonomic work analysis; work analysis as a means for professional training; and a third way that aims to embrace the two former perspectives in projects comprising training and work situations transformation. In this analysis, the importance given to the consideration for the acquired experience throughout a professional course is highlighted, as well as the valorisation of this experience in the scope of projects of transformation of productive processes. In this framework the theme of durable development emerges, despite being dressed up in various meanings that will be characterized in a differential manner. 
ÍNDICE

Palabras claves: análisis ergonómico, formación continua, transformación del trabajo, actividad, desarrollo

Mots-clés: analyse ergonomique, formation continue, transformation du travail, activité, développement

Keywords: ergonomic analysis, continuous training, work transformation, activity, development Palavras-chave: análise ergonómica, formação contínua, transformação do trabalho, actividade ; desenvolvimento

\section{AUTORES}

MARIANNE LACOMBLEZ

Faculdade de Psicologia e de Ciências da Educação Universidade do Porto, Rua Dr. Manuel Pereira da Silva 4200-392 Porto, Portugal

lacomb@fpce.up.pt

\section{RICARDO VASCONCELOS}

Faculdade de Psicologia e de Ciências da Educação Universidade do Porto, Rua Dr. Manuel Pereira da Silva 4200-392 Porto, Portugal

ricardo@fpce.up.pt 